\title{
Temporomandibular joint alterations: two clinical case-reports of bifid condyle and temporomandibular joint ankylosis
}

\author{
Mariana Campos Limongi' \\ https://orcid.org/0000-0001-6090-8350 \\ Flávio Ricardo Manzi ${ }^{1}$ \\ https://orcid.org/0000-0001-9467-5137 \\ José Benedito Fonseca Limongi ${ }^{2}$ \\ https://orcid.org/0000-0003-0181-7832
}

Pontifícia Universidade Católica de Minas Gerais - PUC Minas, Belo Horizonte, Minas Gerais, Brasil.

2 Clínica Limongi, Itabira, Minas Gerais, Brasil.

Conflict of interests: Nonexistent

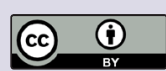

Received on: October 6, 2018 Accepted on: March 14, 2019

Corresponding address: Mariana Campos Limongi

Rua Espírito Santo, 935

CEP: 30160-031 - Belo Horizonte, Minas Gerais, Brasil

E-mail: mariana@clinicalimongi.com.br

\section{ABSTRACT}

The etiology of alterations of the temporomandibular joint, such as ankylosis and bifid condyle, comprises several causes including trauma. However, otological infections cannot be overlooked as a probable cause of alterations of the temporomandibular joint, because the proximity between the external auditory canal and the temporomandibular joint facilitates the spread of infection in the region. This article presents a case-report of a patient with bifid condyle of the temporomandibular joint, in which the patient had no history of facial trauma, but had suffered recurrent otitis infections during her childhood. In parallel, a second case-report is described of temporomandibular joint ankylosis in a 12-year-old patient with a history of facial trauma during her childhood. The purpose of this study was to highlight and emphasize the importance of early diagnosis of temporomandibular joint disorders to avoid the development of facial asymmetries, restore function, esthetics, and the psychological state of the patient.

Keywords: Temporomandibular Joint; Temporomandibular Joint Disorders; Ankylosis; Diagnostic Imaging; Otitis Media 


\section{INTRODUCTION}

The temporomandibular joint (TMJ) is frequently studied in the field of Speech Therapy and Language (pathologies), due to its importance arising from mandibular movements and from efficiency of the stomatognathic functions ${ }^{1}$. The first anatomic descriptions of the TMJ were made by Leonardo da Vinci and Andréas Vesalius in the 15th and 16th centuries $^{2}$. One of the most complete definitions of this joint is that of Madeira (2004) $)^{3}$, who defined it as a sinovial, bilateral, interdependent articulation, with its own, but simultaneous movements, and it was therefore the most complex joint in the human body. It is also the only joint connected to the cranium (spine and shoulder as well) classified as being triaxial; that is; it is capable of performing movements around three axes.

The embryonic development of this region occurs in the 8th week of intrauterine life, in which two widely areas widely separated by mesenchymal cells have been observed in the region of the mandibular head and articular cavity ${ }^{4}$. During development, morphological and functional changes may occur, such as condylar hyperplasia, post-radiotherapy changes, defects associated with diseases or specific syndromes (primary brachial arch syndrome, mandibulofacial dysostosis), bifid condyle, ankylosis, among others ${ }^{5}$.

Bifid condyle is described in the literature as being a structural change of unknown etiology and uncertain pathology. In the majority of cases it is asymptomatic, and is discovered by means of imaging exams for routine purposes. Reports have indicated that the presence of bifid condyle is not determined by age or sex, but some studies have shown its occurrence between the ages of 3 and 67 years, with a mean of 35 years of age ${ }^{6}$. This condition is an uncommon entity with a controversial etiology. It may be developed or acquired, and may rarely be associated with temporomandibular joint ankylosis. Although this type of morphological change is generally associated with trauma, conditions such as the use of teratogenic drugs, genetic inheritance, infection, and exposure to radiation may also cause the development of this anomaly?

TMJ ankylosis may be defined as fusion between the mandible and glenoid cavity, reducing or restricting the articular movements, limiting mastication and inducing esthetic, nutritional, psychological, and social problems. The fusion may be of a fibrous or osseous nature ${ }^{8}$. This condition may occur at any age, however it occurs more frequently in children under the age of 10 years. Its most frequent causes are: traumatic lesions (fractures of the condyle and trauma during birth), infections in the neighborhood of the TMJ; petrositis; intracranial factors; infections in the temporal muscle); and systemic infections ${ }^{9,10}$.

The proximity between the external auditory canal and TMJ facilitates the dissemination of infection, as the articular capsule is fixed to the squamotympanic fissure. Congenital dehiscence of the cartilaginous canal of the squamotimpanic fissure, or the persistence of the foramen of Huschke (foramen tympanicum) may contribute to the diffusion of an infection into the joint. Fusion of the tympanic ring is initially incomplete in its anterior and inferior portions, resulting in an opening (foramen of Huschke) present in up to the fourth or fifth year of the individual's life. This fusion separates the external auditory canal superiorly, and the foramen of Huschke inferiorly; that is to say, it represents the non-ossification of the anterior-inferior portion of the tympanic plate, which is of intramembranous origin. However, this foramen could persist throughout the individual's life. When this occurs, the retrodiscal region of the temporomandibular joint and medial portion of the external auditory canal are separated by soft tissue only, which facilitates the dissemination of infectious processes in the region ${ }^{4}$.

The most common etiological factor of TMJ ankylosis and bifid condyle is associated with trauma ${ }^{11,12}$. Post-traumatic TMJ ankylosis may have various causal factors, among them disc displacement may be one of the most prevalent. This displacement causes absence of a barrier that normally impedes establishment of a bony bridge caused by the post-traumatic responses ${ }^{13}$. While the mandibular condyle fracture site and its relationship with insertion of the lateral pterygoid muscle are factors that determine the future development of bifid condyle ${ }^{7}$.

Therefore, the aim of the present study was to emphasize the relevance of early diagnosis of changes in the TMJ, present a case of bifid condyle without history of trauma, but with recurrent otitis during childhood; and a case of TMJ ankylosis in a 12-year old child who had a history of trauma. Thus, the importance of professionals' knowledge of the area is highlighted to enable early diagnosis with the purpose of avoiding the development of facial asymmetries, re-establishing function, esthetics, and the psychological state of the patient. 


\section{CASE REPORT}

The following two clinical cases reported were conducted in conformity with the Declaration of Helsinki, and were approved by the Research Ethics Committee of the Pontifícia Universidade Católica of Minas Gerais, Protocol Number: 2,704,509. The participants signed the Term of Free and Informed Consent, in accordance with the criteria of Resolution 466/2012, of the National Council of Health.

\section{CASE 1}

The patient, a 24-year-old Caucasian woman, was referred to a private Radiology clinic in the city of Itabira for attendance, to have a panoramic radiograph taken and undergo a tomographic exam of the TMJ, after reporting painful symptoms in the region, and clicking sounds on mouth opening. When evaluating the panoramic radiograph (Figure 1) morphological change was identified in the condyle process on the right side. After undergoing the Cone Beam Computed Tomography exam, condylar bifurcation was diagnosed, as shown in the axial, coronal, and sagittal views of the 3D reconstructions (Figure 2). The patient reported no history of trauma in the region, or presence of neoplasm, tumor formation, or use of obstetric forceps during delivery. She did, however, recall recurrent episodes of ear infection of the purulent type during early childhood.

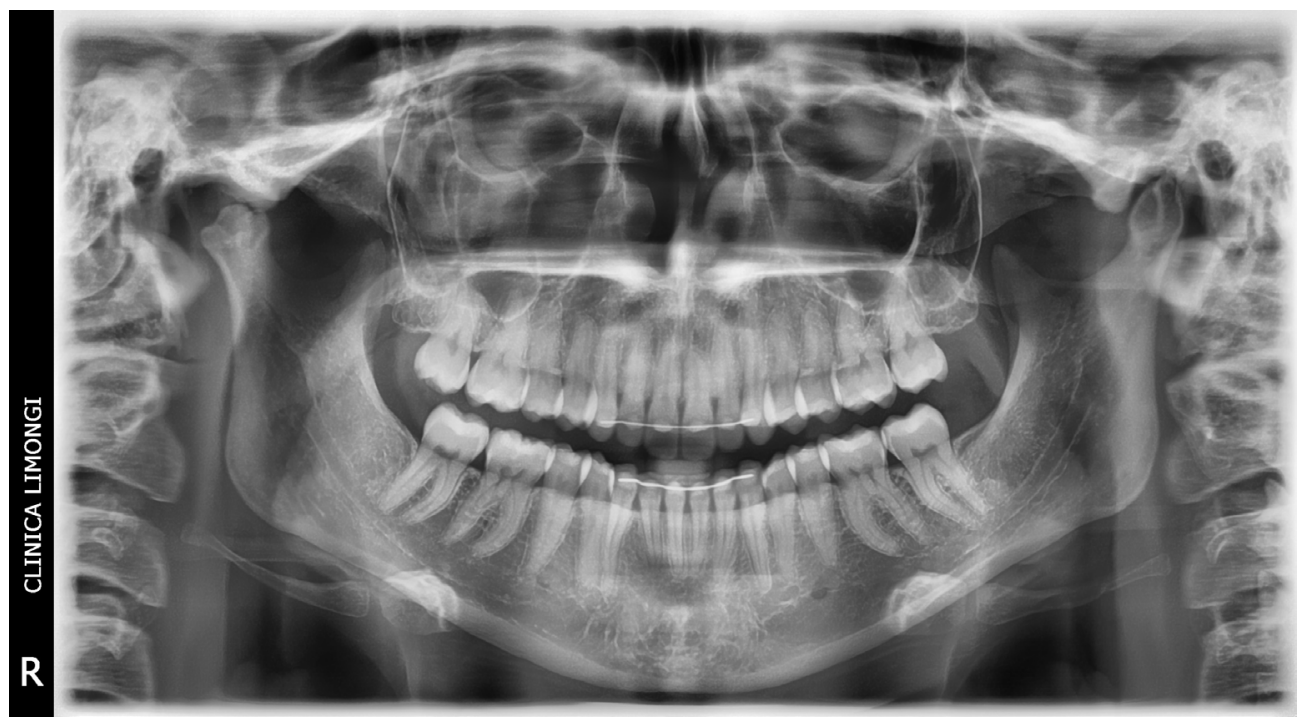

Figure 1. Panoramic radiograph showing condylar bifurcation (shown by the arrow)

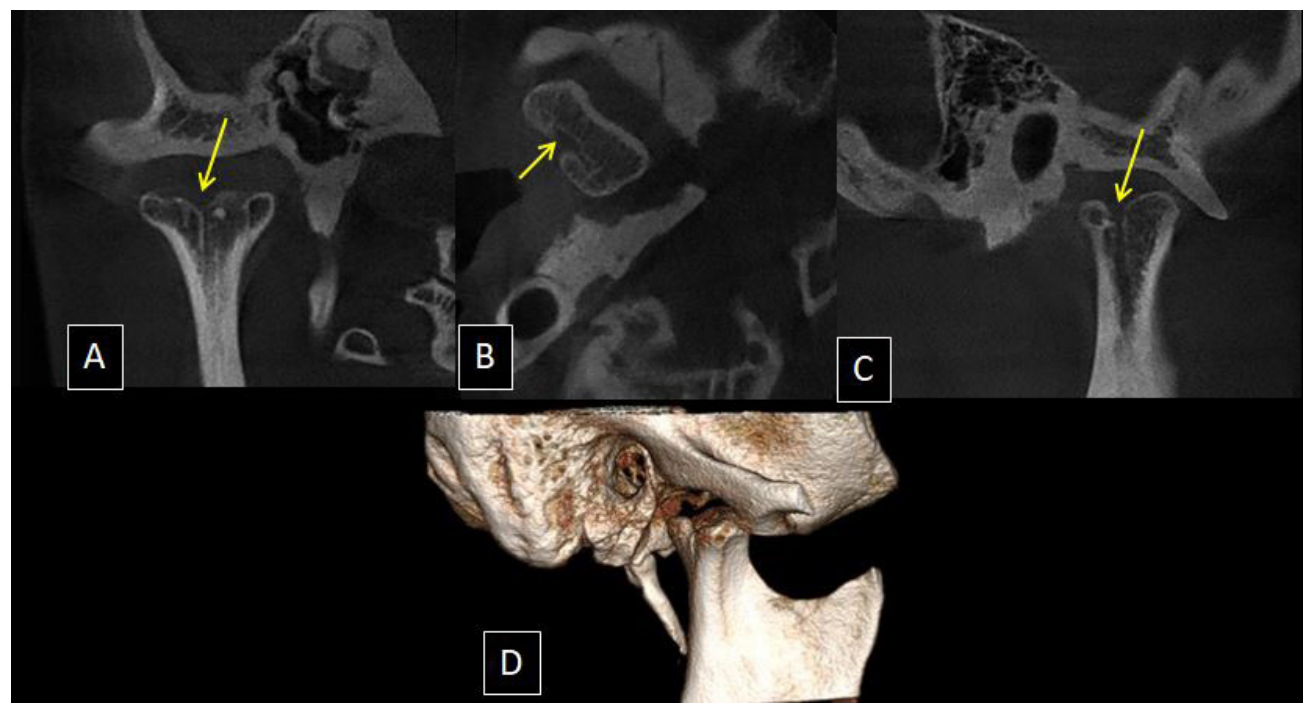

Figure 2. Cone beam computed tomography images of the right side of the temporomandibular joint - coronal view: (A) coronal view; (B) axial view; (C) sagittal view; (D) 3D image; signaling condylar bifurcation 


\section{CASE 2}

The patient, a 12-year-old girl, melanoderma, was referred for attendance at the local health unit at the age of 2 years, after falling off her bicycle. At first, no fracture was diagnosed in the TMJ region, and the patient was discharged. Worth emphasizing is the fact that no terminological exams were performed at this first attendance. After 4 years, her mother observed that she presented sever mouth-opening limitation and facial asymmetry. The patient was referred to Hospital João XXIII, in Belo Horizonte for a new evaluation.

On extraoral physical exam, clear facial asymmetry was observed, with deviation of the chin to the left. In the intraoral exam, Class II malocclusion, anterior open bite, retarded development and bone growth of the dental arches were observed, in addition to maximum mouth opening of $2 \mathrm{~mm}$. Radiographic exam revealed degenerative change in the bone of the mandibular condyle on the left side, with shortening of the left mandibular ramus in comparison with the right side. In view of these characteristics, the patient was submitted to reconstruction surgery. However, she had post-surgical complications, such as cardio-respiratory arrest, and was submitted to tracheostomy. The patient was hospitalized for a period of one year to recover from the post-surgical complications. Due to this prolonged hospitalization, (low masticatory function and stimulus), the surgery was unsuccessful and the patient returned to the initial stage of ankylosis.

Four (4) years after hospitalization, the patient, now 12 years old, returned to the dental office for new evaluation. On clinical examination, severe facial asymmetry and limited mouth opening were identified (Figures 1 and 2). She was submitted to radiographic, panoramic, and cephalometric exams (Figure 3) and later to Cone Beam Computed Tomography (Figure 4). For better assessment, the patient was submitted to helicoidal tomography (Figure 5). Computed tomography revealed fusion between the condylar process and zygomatic bone. The exam provided data for diagnosis of advanced ankylosis of the left temporomandibular joint.

After the exams performed, the patient is in the queue waiting to have a new surgery performed.

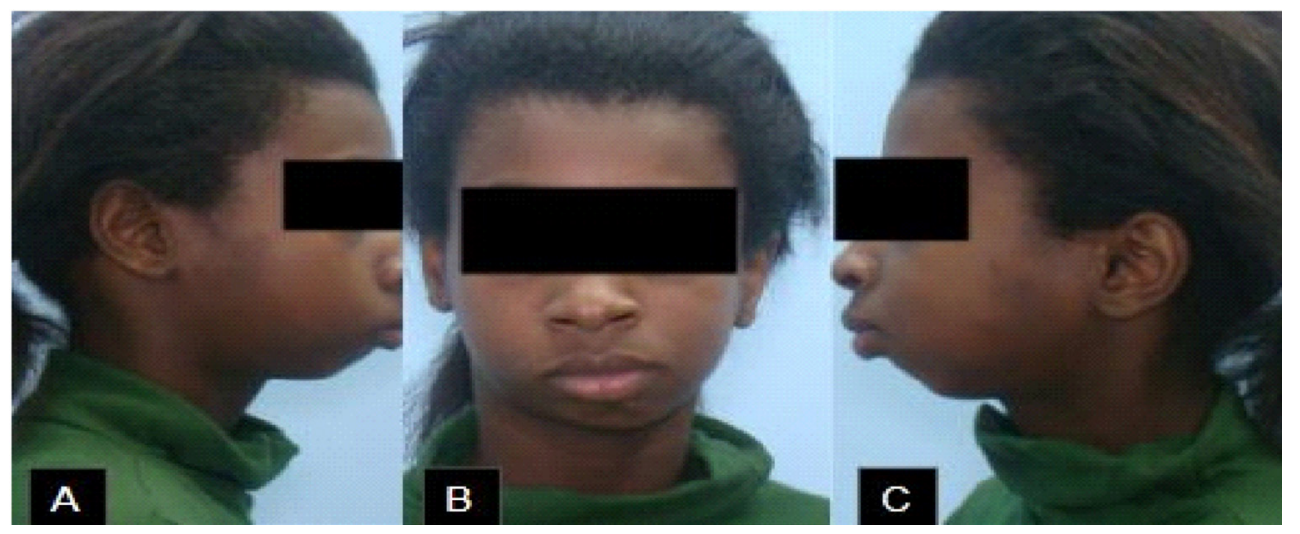

Figure 3. Extraoral photos: $(A)$ right lateral; $(B)$ frontal; $(C)$ left lateral; demonstrating the severe facial asymmetry

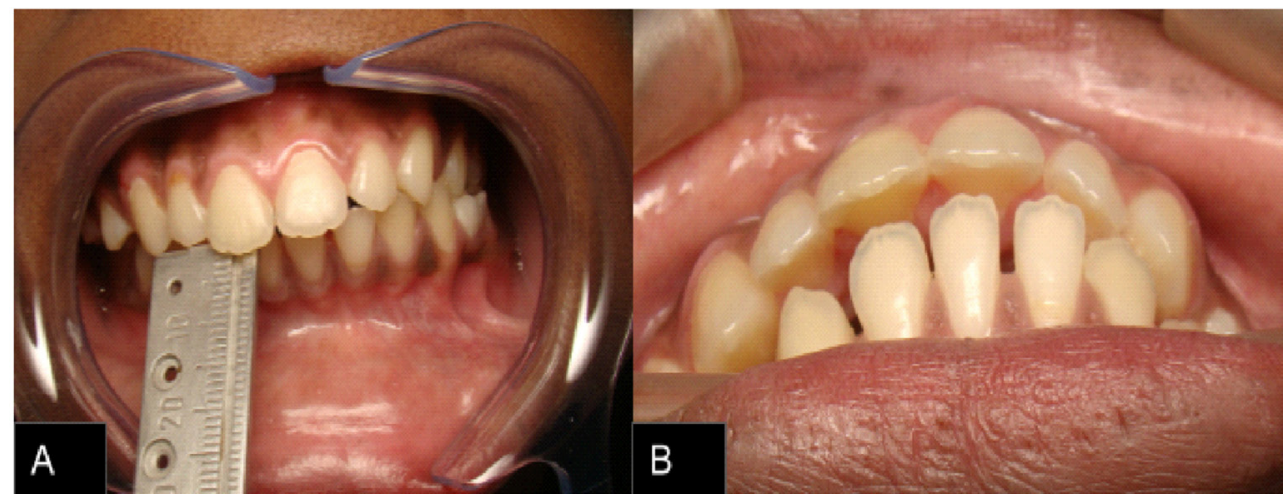

Figure 4. Intraoral photos with open mouth: (A) anterior view, opening 2mm; (B) inferior view. Images demonstrating limitation of mouth opening 


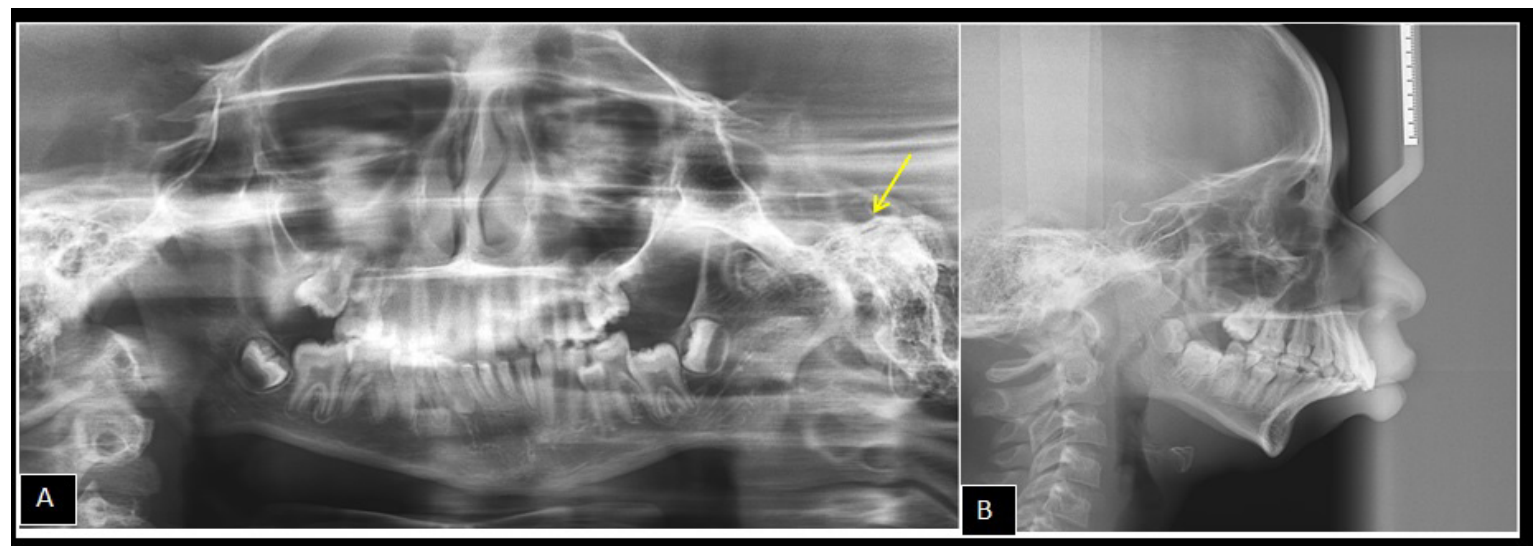

Figure 5. Extraoral radiographs: (A) panoramic and (B) cephalometric. Ankylosis of the temporomandibular joint on the left side

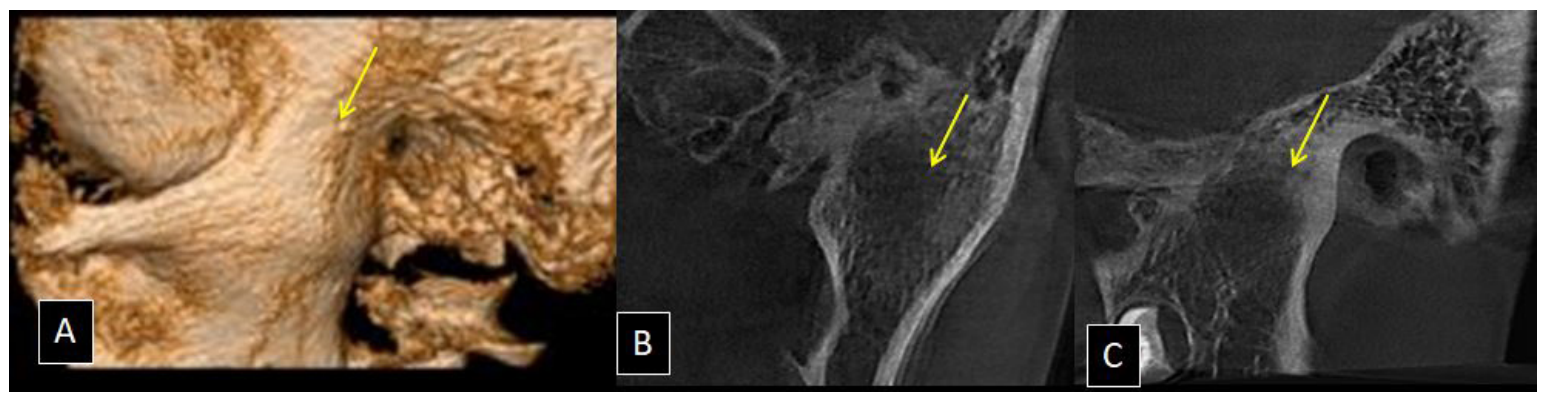

Figure 6. (A) 3D Image of the left side of temporomandibular joint in Cone Beam Computed Tomography; (B) coronal view of the left side of temporomandibular joint in Cone Beam Computed Tomography; (C) sagittal view of the left side of temporomandibular joint in Cone Beam Computed Tomography. Absence of articular space and complete ankylosis of the temporomandibular joint on the left side

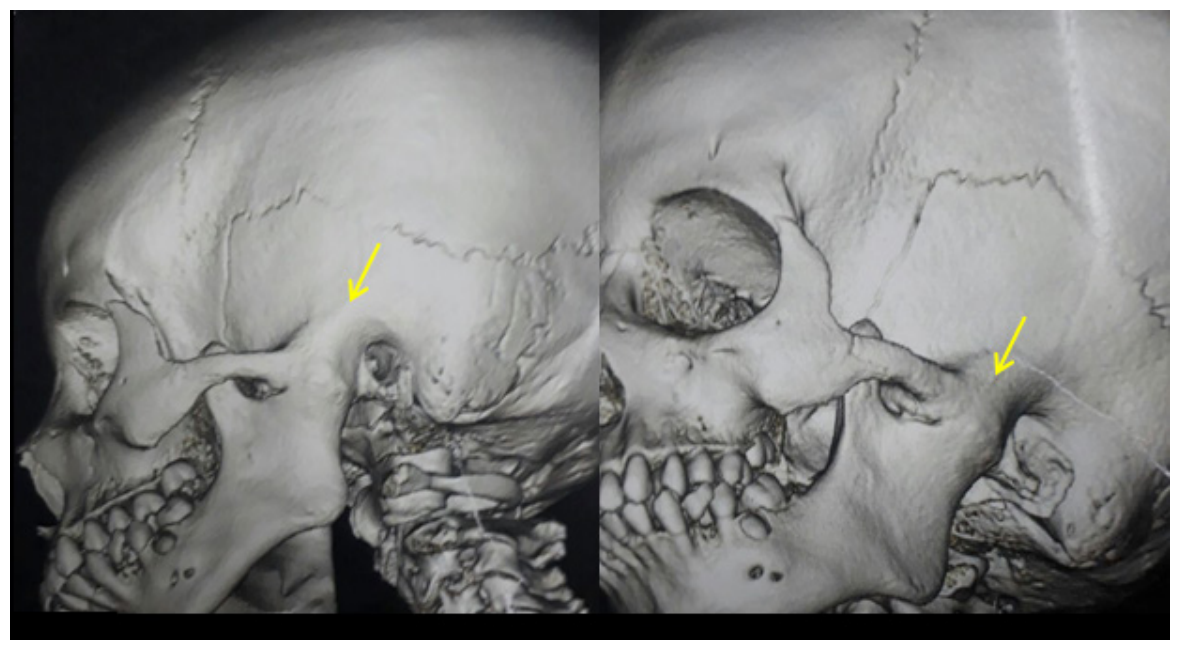

Figure 7. 3D Images of the temporomandibular joint on the left side taken by helicoidal tomography

\section{DISCUSSION}

In 1983, Shafer ${ }^{14}$ and other authors classified ankylosis of the TMJ into two groups: intra-articular ankylosis and extra-articular ankylosis, both classified in degrees: partial or complete and unilateral or bilateral. Intra-articular ankylosis causes progressive destruction of the meniscus, with flattening of the mandibular fossa, thickening of the condyle head and narrowing of the articular space. Ankylosis is basically fibrous, although ossification of the scar may result in union of the bone. On the other hand, extra-articular ankylosis results in immobilization of the temporomandibular joint by fibrosis or ossification, external to the joint itself, as in the cases of infection in the region, or extensive destruction of the articular capsule tissues, as in the case reported. Traumatism in early childhood, such as trauma during delivery by the poor use of obstetric forceps at birth, or accidents resulting from falls, 
may cause condylar fractures. These lesions, when not diagnosed at an early stage, may develop into intra-articular hematomas, followed by fibrosis and later fusion of the bone. In condylar fracture resulting from use of forceps during birth, unilateral or bilateral articular fusion is frequent, with subsequent fibrosis and calcification of the articular space ${ }^{9}$.

ATM ankylosis may be classified into: type I, when there is light to moderate fibro-osseous adhesion; type $\mathrm{II}$, when there is a bone bride that starts from the ramus up to the base of the skull; type III, when there is medial disposition of the fractured condyle and formation of a bone bridge that starts from the ramus and continues to the zygomatic arch and articular fossa; and type 4, when the architecture of the TMS is completely replaced by a large bone mass caused by post-traumatic responses ${ }^{15}$. The present report fits into type IV of Sawhney ${ }^{15}$, because the architecture of the TMJ was completely replaced by a bone mass. The mandibular condyles represent the sites most frequently affected by jaw fractures, capable of reaching a frequency of up to $35 \%$ of the total number of mandibular fractures; with the majority of these fractures resulting from impacts on the region of the mandibular symphysis and/or parasymphysis ${ }^{16}$.

It must be pointed out that the mandibular condyle region is the crucial center of facial growth. Therefore, lesions during childhood and puberty may lead to condylar malformations, including bifid condyle and severe facial asymmetry. Post-fracture recovery and mandibular condyle remodeling - if they involve lateral and medial fragments - have also been associated with the development of ankylosis or bifid condyle. Szentpetery et al. ${ }^{17}$ and other authors have stated that the fracture site, and most probably, its relationship with insertion of the lateral pterygoid muscle may determine the future development of a normal or bifid condyle. The reported existence of two different patterns of bifid condyle may be related to distinct causes for each type. Thus, the authors postulated that the anteroposterior fracture pattern resulted from facial trauma during childhood, and the lateral medial form could be associated with the persistence of the fibrous septs of the condylar cartilage. Although this model is recurrent in the majority of cases, Cowan and Ferguson ${ }^{18}$ gave various examples of bifid condyles that did not fit into this profile. Moreover, the degree of division varies from a superficial sulcus in the condyle to 2 distinct condyles with separate necks. Orientation of the head may be medium lateral (coronal) or anterior-posterior (sagittal).
Although this type of morphological change is generally associated with trauma, conditions such as the use of teratogenic drugs, genetic inheritance, infection, and exposure to radiation may also cause the development of this anomaly ${ }^{7}$. The close relationship between the middle ear, mastoid process, glenoid cavity, and temporomandibular joint helps to spread infections in the region. The bony walls of the pneumatized spaces of the mastoid process are important barriers against the dissemination of infection. However, destruction of these barriers, presence of open sutures in the articular fossa, in addition to retarded ossification of the timpanic plate may facilitate dissemination of infections, such as acute otitis media, acute and chronic mastoiditis to the region of the TMJ. It is also important to emphasize that the presence of the foramen of Huschke would be a probable cause of weakening of the external auditory canal bone structure, with possible tendency to fracture this in cases of traumas and dissemination of infections ${ }^{19}$.

Youngsters are at greater risk for otological infections, due to the immaturity of the auditory tube, and they do not yet have complete bone development of the temporal bone, glenoid cavity, and TMJ. This combination of factors places this age group at high risk for dissemination of infection among these distinct anatomic regions ${ }^{4}$. In the first case reported, it was not possible to establish a specific cause as etiological agent, since the family members did not report the occurrence of an associated trauma event. However, before confirming the etiology as being idiopathic, it is acceptable to speculate the history of recurrent infections could have been a possible factor. The authors had information in the previous clinical history reporting that the patient had recurrent otitis in childhood. At this stage, the bone structures that surround the region of the ear and TMJ were immature, which favored the dissemination of infection and probably compromised development of the mandibular condyle.

The detailed description of the clinical, functional, and radiographic findings would be necessary for establishing a set of pathognomonic signs that may help with recognition of the etiology of the morphological changes in the TMJ. Early diagnosis is important for minimizing the consequences of ankylosis of the TMJ, re-establishing esthetic function and the psychological state of the patient. 


\section{CONCLUSION}

Different factors comprise the etiology of the changes in the temporomandibular joint, such as ankylosis and condylar bifurcation, trauma being the main factor. However, otological infections must not be overlooked as probable causes, as reported in the second case. Therefore, it is determinant for professionals, who work in the area of the stomatognathic system, to know that there are clinical implications resulting from anatomic variations related to the TMJ, facilitating the dissemination of infections in the region. Early diagnosis and multidisciplinary treatment are extremely important for minimizing the consequences of temporomandibular joint disorders. A multidisciplinary team (doctors, otorhinolaryngologists, dentists, speech therapists/audiologists, physical therapists, and psychologists) is fundamental for the treatment of more complex cases such as ankylosis of the TMJ. It is worth emphasizing the importance of anamnesis and a larger number of studies to determine and recognize the mechanisms involved in dysfunctions of the TMJ.

\section{ACKNOWLEDGEMENTS}

The authors thank Prof. José Leonardo Ferreira for kindly helping with the revision of the article.

\section{REFERENCES}

1. Oliveira MFR, Crivello JR. O comportamento da movimentação mandibular em pacientes com disfonia funcional e organofuncional. J. Bras. Fonoaudiol. 2004;5(19):110-7.

2. Zocoli R, Mota EM, Sommavilla A, Perin RL. Manifestações otológicas nos distúrbios da articulação temporomandibular. ACM Arq. Catarin. Med. 2007;36(1):90-5.

3. Madeira MC. Articulação temporomandibular. In: Madeira MC (org). Anatomia da face: bases anátomo-funcionais para a prática odontológica. 5 . ed. São Paulo: Sarvier; 2004. P. 81-96.

4. Horn DSG, Silveira OSA, Carolina DBA, Pires LR, Morais CMF, Seraidarian PI et al. Hipoplasia condylar of probale otologic origin. Rev. CEFAC. 2016;18(3):801-6.

5. Whaites E, Nascimento RM. A articulação temporomandibular. In: Whaites E (org). Radiologia odontológica. 4a edição. Rio de janeiro: Elsevier; 2009 P. 355-69.

6. López-López J, Ayuso-Momero R, Salas EJ, Roselló-Llabrés X. Bifid condyle: review of the literature of the last 10 years and report of two cases. The Journal of Craniomandibular Practice. 2010;28(2):136-40.

7. Faisal M, Ali I, Pal US, Bannerjee K. Bifid mandibular condyle: report of two cases of varied etiology. Natl. J. Maxillofac. Surg. 2010;(1):78-80.

8. Neville BW, Allen CM, Damm DD. Dor facial e doenças neuromusculares. In: Neville BW, Allen CM, Damm DD (Orgs). Patologia oral \& maxilofacial. 2 ed. Rio de Janeiro: Guanabara Koogan, 2004.P. 713-4.

9. Pereira Filho EN, Carvalho Neto LG, Garcia AF, Cavalcanti AL. Anquilose da articulação temporomandibular em criança: relato de caso. Odonto. 2011;19(38):31-8.

10. Miranda SL, Antonini RA. Anquilose da articulação têmporo-mandibular pós-otite média aguda. Rev. Bras. Otorrinolaringol. 1994;60(3):240-2.

11. Komorowska A. Congenital temporomandibular joint ankylosis - a case report. Eur. J. Orthod. 1997;19(3):243-8.

12. McCormick SU, McCormick SA, Graves RW, Pifer RG. Bilateral bifid mandibular condyles: report of three cases. Oral Surg. Oral Med. Oral Pathol. 1989;68(5):555-7.

13. Zhang Y, He DM. Clinical investigation of early post-traumatic temporomandibular joint ankylosis and the role of repositioning discs in treatment. Int J. Oral Maxillofac. Surg. 2006;35(12):1096-101.

14. Shafer WG, Hine MK, Levy BM, Tomisch CE. Doenças dos sistêmas específicos. In: (Orgs). Tratado de Patologia Bucal. 4 ed. Rio de Janeiro: Guanabara S.A, 1987. P. 624-789.

15. Sawhney CP. Bony ankylosis of the temporomandibular joint: follow-up of 70 patients treated with arthroplasty and acrylic spacer interposition. Plast. Reconstr. Surg. 1986; 77(1):29-40.

16. Olson RA, Fonseca RJ, Zeitler DL, Obson DB. Fractures of the mandibule: a review of 580 cases. J. Oral Maxillofac. Surg. 1982;(40):23-8.

17. Szentpetery A, Kocsis G, Marcsik A. The problem of the bifid mandibular condyle. J. Oral Maxillofac. Surg. 1990;48(12):1254-7.

18. Cowan DF, Ferguson MM. Bifid mandibular condyle. Dentomaxillofac. Radiol. 1997;26(1):70-3.

19. Ajduka J, Riesa M, Vagica D, Batos-Tripalo A. Temporomandibular joint fistula into the external ear canal. JLO. 2012;126(8):837-9. 